\title{
Nanoplatforms Based on Plasmonic Nanoparticles for Multitherapy in the Treatment of Cancer ${ }^{+}$
}

\author{
Lilia Arellano ${ }^{1, *}$, BrendaVelasco ${ }^{1}$, Valeria Figueroa ${ }^{1}$, Eva Villar ${ }^{1}$, Adriana Cambón ${ }^{1}$, Abeer A. \\ Almodlej ${ }^{2}$, Silvia Barbosa ${ }^{1}$ and Pablo Taboada ${ }^{1}$ \\ 1 Grupo de Física de Colloides y Polímeros, Facultad de Física e Instituto de Investigaciones Sanitarias, \\ Universidade de Santiago de Compostela, E-15782 Santiago de Compostela, Spain; \\ brendavero.iq@gmail.com (B.V.); valeria.fvelarde@alumnos.udg.mx (V.F.); eva.mailbox1@gmail.com (E.V.); \\ adrianacambonfreire@gmail.com (A.C.); silvia.barbosa@usc.es (S.B.); pablo.taboada@usc.es (P.T.) \\ 2 College of Science, King Saud University, Riyadh 11451, Saudi Arabia; hens.querus@gmail.com \\ * Correspondence: liliagarellanog@gmail.com \\ + Presented at the 2nd International Online-Conference on Nanomaterials, 15-30 November 2020; Available \\ online: https://iocn2020.sciforum.net/.
}

Published: 15 November 2020

In most of the cases, the diagnostic and therapy stages are carried out independently and this lead to delays in the application of the treatments and, therefore, an important risk to the patients' health. To overcome these incoveniences, in the few last years theranostic has reached an important role to join in a unique nanoplatform therapeutic treatment, action and monitoring of the response to simultaneous therapy. Thus, we designed an hybrid nanosystems based on gold nanoparticles capable of simultaneously combining their potential as a photodynamic therapeutic agent (PDT), plasmonic photothermal therapy (PPTT) and/or chemotherapy to kill malignant cells [1-9]. In order to do that, gold nanorods (GNR) were functionalized by the layer-by-layer (LbL) assembly technique using alternate layers of polyelectrolytes (PE): poly (styrene sulfonate) (PSS) and poly-L-lysine (PLL) as anionically and cationically charged polymeric layers, and an outer layer of hyaluronic acid (HA) to provide the hybrid particles with sufficient colloidal stability and steering ability. Doxorrubicin (DOXO) and SiRNA were added by electrostatic interactions to the PSS and PLL layers for providing chemo- and genetic therapy, respectively, controlling the \% weight and encapsulated efficiency of doxorubicin and SiRNA with their calibration curve. To provide the PDT capabilities to the nanoplatform, the green indocyanine photosensitizer (ICG) was previously conjugated to the PLL polymer and assembled into the nanoplatform by electrostatic interactions, checking its efficiency with the fluorometer. In this way, hybrid particles formed by GNR coated with PSS/DOXO/PLL @ ICG@SiRNA/HA layers were obtained, in which the therapeutic PDT activity of the dye ICG, chemoactivity of DOXO and the photothermal properties of the plasmonic metal nanoparticles can be simultaneously be applied for efficient cancer therapeutics. Nanoplatforms were characterizated by UV-Vis, FTIR and RAMAN spectroscopy, $\zeta$-potential and TEM. In addition, PPTT therapy of the nanoplatforms was evaluated at different irradiation powers. Finally, single oxygen $\left({ }_{1} \mathrm{O}^{2}\right)$ production under NIR light excitation by the hybrid nanosystem was evaluated in vitro at several power intensities by means of fluorescence and absorbance spectroscopies and fluorescent microscopy.

Acknowledgments: This work was supported by Agencia Estatal de Investigación (AEI) through Project MAT2016-80266-R, and Xunta de Galicia (Grupo de Referencia Competitiva ED431C 2018/26; Agrupación Estratégica en Materiales-AEMAT ED431E 2018/08). FEDER funds are also acknowledged.

\section{References}

1. Alatorre-Meda, M.; Alvarez-Lorenzo, C.; Concheiro, A.; Taboada, P. Smart Materials for Drug Delivery; The Royal Society of Chemistry: Cambridge, UK, 2013; Chapter 12, Volume 1, p. 304.

2. Fomina, N.; Sankaranarayanan, J.; Almuitari, A. Adv. Drug Deliv. Rev. 2012, 64, 1005.

3. Lorenzo, C.A.; Bromberg, L.; Concheiro, A. Photochem. Photobiol. 2009, 85, 848. 
4. Bardhan, R.; Lal, S.; Joshi, A.; Halas, N.J. Acc. Chem. Res. 2011, 44, 936.

5. Celli, J.P.; Spring, B.Q.; Rizvi, I.; Evans, C.L.; Samkoe, K.S.; Verma, S.; Pogue, B.W.; Hasan, T. Chem. Rev. 2010, 110, 2795.

6. Rai, P.; Mallidi, S.; Zheng, X.; Rahmanzadeh, R.; Mir, Y.; Elrington, S.; Khurshid, A.; Hasan, T. Adv. Drug Deliv. Rev. 2010, 62, 1094.

7. Zhao, Y. Macromolecules 2012, 45, 3647.

8. Skirtach, A.G.; Antipov, A.A.; Shchukin, D.G.; Sukhorukov, G.B. Langmuir 2004, 20, 6988.

9. Oerlemans, C.; Bult, W.; Bos, M.; Storm, G.; Nijsen, J.F.W.; Hennink, W.E. Pharm. Res. 2010, $27,2569$.

Publisher's Note: MDPI stays neutral with regard to jurisdictional claims in published maps and institutional affiliations.

(C) 2020 by the authors. Submitted for possible open access publication under the terms and conditions of the Creative Commons Attribution (CC BY) license (http://creativecommons.org/licenses/by/4.0/). 